\title{
DESCRIÇÃO ANATÔMICA DE CALYCOPHYLLUM MULTIFLORUM GRISEB. (RUBIACEAE) ${ }^{1}$
}

\author{
TALITA BALDIN² JOSÉ NEWTON CARDOSO MARCHIORI ${ }^{3}$
}

\section{RESUMO}

O lenho de Calycophyllum multiflorum Griseb. é anatomicamente descrito e ilustrado. A estrutura microscópica é comparada com referências da literatura, destacando-se: vasos extremamente numerosos, em múltiplos radiais, menos comumente solitários e racemiformes; elementos vasculares de comprimento médio, com apêndices longos; parênquima axial ausente; raios heterogêneos, em sua maioria com duas células de largura; e fibras libriformes septadas, de paredes delgadas a espessas.

Palavras-chave: Anatomia da madeira, Calycophyllum multiflorum, Ixoroideae, Rubiaceae.

\section{ABSTRACT}

[Wood anatomy of Calycophyllum multiflorum Griseb. (Rubiaceae)].

The wood of Calycophyllum multiflorum Griseb. is anatomically described and illustrated. The microscopic structure is compared with literature references, being pointed out: extremely numerous vessels, in radial multiples, less commonly round solitary and in clusters; medium length vascular elements; absent axial parenchyma; heterogeneous rays, mainly with two cells wide; and thin to thick-walled libriform septate fibers.

Key words: Wood anatomy, Calycophyllum multiflorum, Ixoroideae, Rubiaceae.

\section{INTRODUÇÃO}

A família Rubiaceae Juss., deriva seu nome do gênero Rubia L. (Rubium, em latim), em referência à tinta vermelha produzida pelas raízes de plantas deste gênero, utilizadas como corantes no tingimento de tecidos (Cronquist, 1981). De grande representatividade nas Angiospermas, reúne cerca de 550 gêneros e 9.000 espécies (Judd et al., 2009), concentradas nas regiões mais quentes do globo (Chiquieri et al., 2004).

De acordo com Souza \& Lorenzi (2008), ocorrem cerca de 120 gêneros e 2.000 espécies

1 Recebido em 04-8-2014 e aceito para publicação em 21-11-2014.

2 Engenheira Florestal, doutoranda do Programa de PósGraduação em Engenharia Florestal, Universidade Federal de Santa Maria. talita.baldin@ @otmail.com

3 Engenheiro Florestal, Professor Titular, Dr., Departamento de Ciências Florestais, Universidade Federal de Santa Maria. Bolsista de Produtividade em Pesquisa (CNPq-Brasil).marchiori@pq.cnpq.br de Rubiáceas na flora brasileira, distribuídas nas diversas formações vegetacionais, embora com maior representatividade na Mata Atlântica e, especialmente, no estrato arbustivo (Gomes, 1996).

De hábitos variados, a família reúne ervas, subarbustos, arbustos, árvores, escassas lianas e raras epífitas (Hillia Jacq., por exemplo). Em campo, as Rubiáceas são facilmente reconhecidas pelas estípulas interpeciolares comumente conatas, por vezes transformadas em folhas ou espinhos (Taylor et al., 2007), bem como pelas folhas simples, geralmente oposto-cruzadas, de margem inteira e venação peninérvia, com pequenas domácias na axila abaxial das nervuras laterais.

Segundo Bremer (2009), o gênero Calycophyllum A. DC. insere-se na subfamília Ixoroideae e tribo Condamineeae, reunindo, até o presente momento, cerca de 20 binômios. Tratam-se de árvores de porte médio a grande, endêmicas da América tropical e, na flora brasileira, da região Amazônica. 
Embora pouco variável, a morfologia do gênero permite a distinção de espécies mediante características de folhas e flores. As folhas, oposto-decussadas, ovadas, elípticas ou obovadas, são glabras ou hirtelas, coriáceas ou subcoriáceas, por vezes com domácias na axila das nervuras secundárias. A sépala foliácea, muito conspícua, explica, inclusive, a nomenclatura do gênero.

Calycophyllum multiflorum Griseb. recebe os nomes comuns de "palo-branco" e "ibirámoroti", devido à coloração esbranquiçada da casca. É espécie nativa no noroeste da Argentina (Formosa, Jujuy e Salta), sudeste da Bolívia, centro e noroeste do Paraguai e, no Brasil, no estado do Mato Grosso (Record \& Hess, 1943). Árvore de até $30 \mathrm{~m}$ de altura e $30-70 \mathrm{~cm}$ de diâmetro, apresenta tronco geralmente reto, esbelto, fornecendo toras longas, de casca esbranquiçada, com fissuras longitudinais pouco profundas. Por sua massa específica, textura fina, grã direita e coloração uniforme, a madeira é indicada para fabricação de veículos, carpintaria e setor moveleiro. O fuste reto também a recomenda para postes telefônicos (Bacigalupo, 1968).

As espécies de Calycophyllum foram pouco investigadas até o presente momento sob o ponto de vista anatômico, motivando a realização do presente estudo.

\section{REVISÃO DE LITERATURA}

Deve-se a Van Riemsdijk, no século XVIII (Jansen et al., 2002), um dos primeiros estudos anatômicos em Rubiaceae, que trata da descrição anatômica do lenho de Coffea L. Ao final do século XIX, Solereder (1893) resumiu observações preliminares de características anatômicas para a família.

Já no século XX, Moll \& Janssonius (1926) publicaram a anatomia de vinte e seis gêneros de Rubiaceae da Índia. Uma compilação de características anatômicas da família, com 150 gêneros, foi reunida por Metcalfe \& Chalk (1957) em "Anatomy of Dicotyledons".
As Rubiaceae são surpreendentemente uniformes no tocante à estrutura da madeira (Chang, 1951), especialmente se levado em conta o grande número de espécies, visto ser a quarta família mais numerosa do Reino Vegetal. Esta é, provavelmente, uma das razões pelas quais a Anatomia Sistemática da madeira em Rubiaceae foi pouco explorada até o presente momento.

Metcalfe \& Chalk (1972) registram as seguintes características anatômicas para a família: vasos tipicamente pequenos, médios em alguns gêneros, numerosos a muito numerosos; poros exclusivamente solitários ou em múltiplos radiais de 4 ou mais, raramente com porosidade em anel; elementos vasculares de comprimento médio a longo; placas de perfuração simples; pontoações ornamentadas, alternas, pequenas a diminutas; e ausência de espessamentos espiralados. Salvo exceções, o parênquima axial é tipicamente apotraqueal nas espécies com fibras não septadas, e ausente nas com septos em fibras. Os raios, estreitos e heterogêneos em 70\% dos gêneros, apresentam 1-3 células de largura (8-10 em algumas espécies), e 4 ou mais fileiras marginais de células quadradas e eretas. As fibras, muito curtas a moderadamente longas, são providas ou não de septos, e apresentam pontoações simples ou areoladas (KoekNoorman, 1972).

As madeiras de Rubiaceae são classificadas em dois grupos principais, segundo KoekNoorman (1977) e Jansen et al. (2002): o "Tipo I", com poros predominantemente solitários, parênquima apotraqueal difuso, difuso-em-agregados e/ou em faixas, raios estreitos, de largas margens unisseriadas, e fibras não septadas, de pontoações distintamente areoladas; e o "Tipo II", com poros em múltiplos radiais, parênquima axial ausente ou paratraqueal escasso, raios grandes e fibras septadas, de pontoações simples.

Para o lenho de Calycophyllum, Record \& Hess (1943) citam: vasos em múltiplos radiais de 4 ou mais; parênquima axial ausente; raios de dois tamanhos distintos, com 4 ou mais célu- 
las de largura, ocasionalmente com cristais; e fibras septadas.

\section{MATERIAL E MÉTODOS}

O material em estudo consiste de discos de madeira do tronco, recebidos por permuta do Jodrell Laboratory (Kew Gardens, Londres), do Instituto de Pesquisas Tecnológicas do estado de São Paulo (IPT) e da Black Forest Academy (BFA, Alemanha).

Para a descrição anatômica da madeira foram examinadas nove amostras, constando, para as mesmas, os seguintes registros: 16581 e 8217 (BFA); 9434, 128, 9661, 9542, 3717 e 45 (IPT), e 4187 (KEW).

Para confecção de lâminas de cortes anatômicos, foram extraídos três corpos-de-prova de cada amostra $(3 \times 3 \times 3 \mathrm{~cm})$, devidamente orientados para a obtenção de cortes nos planos transversal (X), longitudinal radial (R) e longitudinal tangencial (T). Um quarto bloquinho foi também retirado, com vistas à maceração. A montagem das lâminas foi realizada no Laboratório de Anatomia da Madeira da Universidade Federal do Paraná, de acordo com a técnica padrão (Burger \& Richter, 1991). Para a dissociação do tecido lenhoso, usou-se o método de Franklin modificado (Kraus \& Arduin, 1997).

A descrição qualitativa do lenho foi baseada nas recomendações do IAWA Committee (1989), com exceção da percentagem dos distintos tecidos, da altura e largura de raios (inclusive de seu corpo e margens, em número de células), bem como da espessura da parede de fibras e vasos, aspectos não contemplados na referida norma. A determinação da fração dos diferentes tecidos foi obtida com um contador de células, segundo metodologia recomendada por Marchiori (1980).

Os caracteres anatômicos foram medidos em microscópio binocular Carl Zeiss, provido de ocular com escala graduada, no Laboratório de Anatomia da Madeira da Universidade Federal de Santa Maria. As fotomicrografias foram to- madas em microscópio Leica DM 1000, equipado com câmera digital Olympus Camedia CX40, no Laboratório de Anatomia da Madeira da UFSM/CESNORS. O processamento das imagens foi realizado com o auxílio do programa CorelDRAW, X7 (64 Bit).

No texto descritivo, os dados quantitativos das características anatômicas referem-se à média (x) e desvio padrão (s), seguido pelos valores mínimo e máximo observados.

\section{DESCRIÇÃO ANATÔMICA}

Aspectos gerais: tecido lenhoso composto de fibras (40\%), vasos (38\%) e raios (22\%). Anéis de crescimento distintos, marcados por camadas de fibras radialmente estreitas no lenho tardio, de paredes mais espessas e lignificadas, bem como pelo pequeno alargamento de células radiais no limite do anel (Figura 1A, B).

Vasos: frequentemente em contato com raios (Figura 1B), de seção arredondada, tendente a oval $(42 \pm 9(15-60) \mu \mathrm{m})$, e paredes espessas $(4 \pm 1(1-10) \mu \mathrm{m})$. Porosidade difusa, uniforme. Vasos extremamente numerosos $(434 \pm 47$ (322-549) poros $/ \mathrm{mm}^{2}$ ), predominantemente em múltiplos radiais de $2-11(70 \%)$, menos comumente solitários (24\%), com escassos racemiformes $(6 \%)$ de 3-10 unidades (Figura 1A). Elementos vasculares de comprimento médio $(627 \pm 122,0(350-910) \mu \mathrm{m})$, com placas de perfuração simples, oblíquas (Figura 1E), desprovidos de espessamentos helicoidais e estriações na parede. Apêndices, longos (94 \pm $56(25-290) \mu \mathrm{m})$, em ambas ou em apenas uma extremidade. Pontoações intervasculares alternas, arredondadas, ornamentadas (Figura 1F), pequenas $(5 \pm 1(4-8) \mu \mathrm{m})$; abertura lenticular, horizontal, inclusa. Pontoações raio-vasculares, semelhantes às intervasculares, embora ligeiramente menores ( $3 \pm 1$ (3-5) $\mu \mathrm{m})$. Tilos, ausentes.

Parênquima axial: ausente.

Raios: heterogêneos, de dois tamanhos distintos, em número de $12 \pm 2$ (8-16) raios $/ \mathrm{mm}$. Raios unisseriados (29\%), de $267 \pm 114$ (80660) $\mu \mathrm{m}$ de altura, com $6 \pm 3$ (2-13) células, e 



FIGURA 1: Aspectos anatômicos do lenho de Calycophyllum multiflorum. A - Limites de anel de crescimento, porosidade difusa, poros extremamente numerosos, solitários, em múltiplos radiais e racemiformes (seção transversal). B - Mesmo plano anatômico, destacando fibras de paredes achatadas radialmente no limite do anel e vasos em contato frequente com células de raio. $\mathrm{C}$ - Raio heterogêneo, com células procumbentes, no centro, e margens de células quadradas e eretas (seção longitudinal radial). D - Mesma seção, em maior aumento, salientando fibras libriformes septadas, depósitos e nanocristais no parênquima radial. E - Seção longitudinal tangencial, evidenciando raios uni e bisseriados, e elementos vasculares com placas de perfuração simples, oblíquas. F - Vasos com pontoações intervasculares alternas, ornamentadas, diminutas, e fibras septadas (seção longitudinal tangencial) 
$15 \pm 3(8-25) \mu \mathrm{m}$ de largura, compostos de células quadradas e eretas. Os multisseriados, em sua maioria com duas células de largura (67\%), raros trisseriados (4\%) (Figura 1A); de $384 \pm$ 99 (210-650) $\mu \mathrm{m}$ de altura, com $14 \pm 4$ (6-22) células, e $26 \pm 4$ (15-38) $\mu \mathrm{m}$ de largura, reunindo células procumbentes, no centro (2-19), e 15 fileiras marginais de células quadradas e eretas (Figura 1C). Raios fusionados, presentes. Células perfuradas, presentes. Células envolventes e latericuliformes, ausentes.

Fibras: libriformes, septadas (Figura 1D, F), com pontoações simples em fenda vertical, restritas às faces radiais da parede. Fibras de comprimento médio $(1257 \pm 269(90-1780) \mu \mathrm{m})$, de paredes delgadas a espessas $(6 \pm 1(3-10) \mu \mathrm{m})$. Espessamentos helicoidais, ausentes. Fibras gelatinosas, não observadas.

Outros caracteres: depósitos e nanocristais em células de raio (Figura 1D). Canais intercelulares, canais celulares, cistos glandulares, estrutura estratificada, sílica, floema incluso, células mucilaginosas e máculas medulares, ausentes.

Observação: Das nove amostras analisadas no presente estudo a BFA 8217 não condiz com sua real identificação, ou seja, não corresponde à Calycophyllum multiflorum. Esta conclusão, baseia-se na análise anatômica, visto que a mesma apresenta características incompatíveis com o gênero, salientando-se o parênquima axial proeminente, que ultrapassa $50 \%$ do volume da madeira (Figura 2A, B, C e D). Este tipo celular é ausente ou muito escasso em espécies de Calycophyllum, conforme Record \& Hess (1943). Além deste aspecto, o material analisado contém raras fibras septadas (Figura 2E) e pontoações intervasculares de diâmetro maior do que o observado no gênero em estudo (Figura 2F), de acordo com Record \& Hess (1943), Léon (2011) e Richter \& Dallwitz (2009).

\section{ANÁLISE ANATÔMICA}

O conjunto de caracteres observados no lenho de Calycophyllum multiflorum está de acordo com o padrão descrito por Record \& Hess
(1949), Koek-Noorman (1972) e Metcalfe \& Chalk (1972) para o conjunto das Rubiaceae. A espécie, no entanto, não atende aos padrões anatômicos citados por Koek-Noorman (1972) e Jansen et al. (1997, 1999) para a subfamília Ixoroideae: vasos solitários, menos comumente em curtos múltiplos radiais; fibrotraqueóides; e parênquima axial difuso, difuso-em-agregados ou em pequenas linhas marginais.

A estrutura do lenho de Calycophyllum multiflorum determina sua inclusão no tipo II de Rubiaceae, de acordo com Koek-Noorman (1977) e Jansen et al. (2002), por apresentar: poros predominantemente em múltiplos radiais; parênquima axial ausente; raios grandes (2-4 células ou mais), com poucas camadas de células quadradas e eretas na margem; e fibras septadas com pontoações simples.

Calycophyllum multiflorum apresenta poros extremamente numerosos $\left(\square 100\right.$ poros $\left./ \mathrm{mm}^{2}\right)$, arredondados ou ovais, e de diâmetro pequeno $(\leq 50 \mu \mathrm{m})$, de acordo com IAWA Committee (1989). Os resultados, coincidem com referências de Tortorelli (1956) para a espécie na Argentina (30-50-70 $\mu \mathrm{m})$, valores que, conforme $\mathrm{o}$ autor, conferem homogeneidade à madeira.

Cabe salientar que o diâmetro de poros é caráter importante em fisiologia vegetal, interferindo de maneira direta na condução de água e substâncias minerais na planta. Segundo Zang et al. (1992), à medida que aumenta o diâmetro de vasos, também cresce a eficiência condutiva e diminui a segurança ou vida útil da estrutura condutora, havendo uma relação inversa do caráter com a frequência de vasos. No entanto, vasos estreitos são mais seguros, uma vez que, encontrando-se em maior número, garantem maior segurança no deslocamento de água, principalmente no que se refere à embolia celular (Baas et al., 1983).

No material descrito, tais relações são confirmadas, posto que o lenho apresenta poros abundantes e de pequeno diâmetro. Analisados, isoladamente, ambos os caracteres favorecem a eficiência condutiva no lenho, mesmo na vigência de prolongada estação seca. 

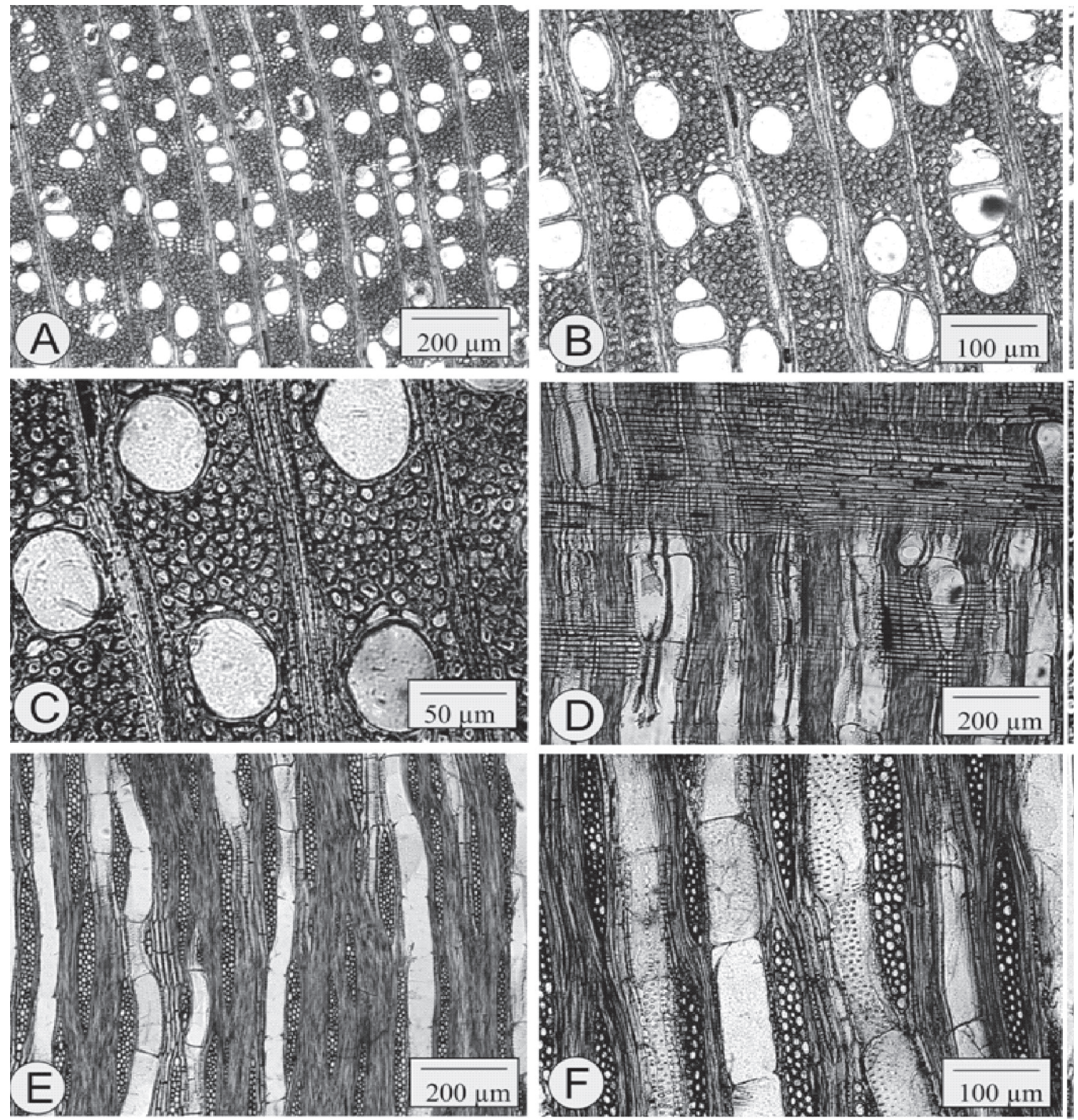

FIGURA 2: Fotomicrografias do lenho da amostra BFA 8217. A - Parênquima paratraqueal abundante (seção transversal). B, C - Mesma seção, em maior aumento. D - Parênquima axial, visto em seção longitudinal radial. E - Fibras não septadas e parênquima axial (seção longitudinal tangencial). F-Mesma seção, em maior aumento, destacando pontoações intervasculares nitidamente maiores, incompatíveis com Calycophyllum multiflorum. 
Para Calycophyllum multiflorum não foram observados tilos, contrariamente ao afirmado por Tortorelli (1956) e Richter \& Dallwitz (2009), que referem o caráter para amostras da Argentina. A ausência do mesmo pode ser facilmente explicada pelo reduzido diâmetro de $\operatorname{vasos}(<100 \mu \mathrm{m})$ e pontoações (média de $5 \mu \mathrm{m}$ ), aspectos limitantes na formação de tiloses, segundo Appezzato-da-Glória \& Carmello-Guerreiro (2003).

No material investigado não se encontrou parênquima axial, corroborando Record \& Hess (1943), que referem a ausência do caráter ou sua ocorrência extremamente rara em Calycophyllum, bem como a estreita relação entre a inexistência de parênquima axial e a presença de fibras septadas, referida por Tortorelli (1956) como caráter constante no gênero e, por Metcalfe \& Chalk (1972), para o conjunto das Rubiaceae.

No tocante aos raios, são comuns dois ou três segmentos multisseriados num mesmo raio em seção tangencial, unidos por segmentos unisseriados, de modo a elevar a altura de um único raio a mais de $1 \mathrm{~mm}$, por vezes. Esse caráter, denominado raio fusionado, é de larga ocorrência na espécie investigada, tendo sido mencionado para Calycophyllum multiflorum, por Tortorelli (1956), e para C. candidissimum, por Baldin \& Marchiori (2015). Raios fusionados são também frequentes em outras espécies de Rubiaceae, tais como em Simira glaziovii, S. pikia, S. rubra (Callado \& Silva Neto, 2003), Randia armata (Marchiori, 1987) e Cephalanthus glabratus (Siegloch et al., 2011a); cabe ressaltar, todavia, que o caráter não é referido para a família, por Record \& Hess (1949), Metcalfe \& Chalk (1972) e Lens et al. (2000).

Células perfuradas de raio, embora escassas, foram encontradas na margem de raios uni e multisseriados. Essas células, mais facilmente visualizadas no plano longitudinal radial, interligam dois vasos e/ou conectam-se a outras células de mesma natureza, mediante placas de perfuração simples. Vale ressaltar que a larga ocorrência desta peculiaridade anatômica, tem sido utilizada na diferenciação de gêneros e espécies de Rubiaceae.

$\mathrm{Na}$ literatura anatômica sobre Calycophyllum, a ocorrência de células perfuradas não foi reportada para $C$. candidissimum, por autores como Kribs (1968), Koek-Noorman (1972), Nardi \& Edlmann (1992), nem para e C. multiflorum (Tortorelli, 1956; Richter \& Dallwitz, 2009). Léon (2011) e Baldin \& Marchiori (2015), no entanto, indicam a presença de tais células em $C$. candissimum e $C$. venezuelense, corroborando o observado no presente estudo.

\section{REFERÊNCIAS BIBLIOGRÁFICAS}

APPEZZATO-DA-GLÓRIA, B.; CARMELLOGUERREIRO, S.M. Anatomia vegetal. Viçosa: UFV, 2003. $438 \mathrm{p}$.

BAAS, P.; WHEELER, E.; FAHN, A. Some ecological trends in vessel characters. IAWA Bulletin, v. 4, p. 141-159, 1983.

BACIGALUPO, M. N. Sinopsis preliminar del género Calycophyllum (Rubiaceae). Darwiniana, v. 14(4), p. 639-653, 1968.

BALDIN, T., MARCHIORI, J.N.C. Anatomia da madeira de Calycophyllum candidissimum (Vahl) DC. (Rubiaceae). Balduinia, n. 48, p.23-28, 2015.

BREMER, B. A review of molecular phylogenetic studies of Rubiaceae. Annals of the Missouri Botanical Garden, v. 96, p. 4-26, 2009.

BURGER, L.M.; RICHTER, H.G. Anatomia da Madeira. São Paulo: Ed. Nobel. 1991. 154 p.

CHIQUIERI, A.; DI MAIO, F.R.; PEIXOTO, A.L. A distribuição geográfica da família Rubiaceae Juss. na Flora Brasiliensis de Martius. Rodriguésia, v. 55, n. 84, p. 47-57, 2004.

CALLADO, C.H.; SILVA NETO, S.J. da. Anatomia do lenho de três espécies do gênero Simira Aubl. (Rubiaceae) da Floresta Atlântica no estado do Rio de Janeiro. Rodriguésia, v. 54, n. 83, p. 23 33, 2003.

CHANG, Y.R, Anatomy of wood and bark in the Rubiaceae. 1951. 374 f. Dissertação (Doctoral dissertation) - University of Michigan, Michigan, 1951.

CRONQUIST. A. An integrated system of classification of flowering plants. New York: Columbia Univ. Press. 1981. 1262 p. 
GOMES, M. Rubiaceae. In: LIMA, M.P.M. de; GUEDES-BRUNI, R.R. (Org.). Reserva ecológica de Macaé de Cima, Nova Friburgo - RJ: Aspectos florísticos das espécies vasculares. Rio de Janeiro: Jardim Botânico, 1996. v. 2, p. 345-426.

IAWA COMMITTEE. IAWA list of microscopic features for hardwood identificacion. IAWA Bulletin, v. 10, n. 3, p. 218-359, 1989.

JANSEN, S.E.; ROBBRECHT, H.; BEECKMAN, H; SMETS, E. Comparative wood anatomy of African Coffeeae (Rubiaceae-Ixoroideae). Belg. J. Bot. 130: 47-58. 1997.

JANSEN, S.; BLOCK, P.; BEECKMAN, H.; SMETS, E. Systematic wood anatomy of the Pavetteae (Rubiaceae-Ixoroideae). Syst. Geogr, v. 68, p. 113-133. 1999.

JANSEN, S.; ROBBRECHT, E.; BEECKMAN, H.; SMETS, E. A survey of the systematic wood of the Rubiaceae. IAWA Bulletin, v. 23, n. 1, p. 167, 2002.

JUDD, W.S.; CAMPBELL, C.S.; KELLOGG, E.A. Sistemática vegetal: Um enfoque Filogenético. Porto Alegre: Artmed, 2009. p. 471-475.

KOEK-NOORMAN, J. The Wood Anatomy of Gardeniae, Ixoreae and Mussaendeae (Rubiaceae). Acta Botanica Neerlandica, v. 21, n. 3, p. 301-320, 1972.

KOEK-NOORMAN, J. Systematische Holzanatomie einiger Rubiaceen. Ber. Deut. Bot. Ges., v. 90, p. 183-190, 1977.

KRAUS, J. E.; ARDUIN, M. Manual básico de métodos em morfologia vegetal. Rio de Janeiro: EDUR, 1997. 198 p.

KRIBS, D. Comercial foreign woods on the American market. New York: Dover Publications Inc., 1968. 241 p.

LEÓN. H.; WILLIAMS J. Anatomía de la madera de 31 especies de Rubiaceae en Venezuela. Acta Botánica Venezuelica, v. 34, n. 2, p. 347-379, 2011.

LENS, F.; JANSEN, S.; ROBBRECHT, E.; SMETS, E. Wood anatomy of the Vanguerieae (Ixoroidea e Rubiaceae), with special emphasis on some geofrutices. IAWA Bulletin, v. 21, n. 4, p. 443455, 2000.

MARCHIORI, J.N.C. Anatomia da madeira de limoeiro-do-mato, Randia armata (Sw.) DC. Ciências Rurais, Santa Maria, v. 17, n. 1, p. 39-48, 1987.

MARCHIORI, J.N.C. Estudo anatômico do xilema secundário de algumas espécies dos gêneros
Acacia e Mimosa, nativas no estado do Rio Grande do Sul. 1980. 186 f. Dissertação (Mestrado em Engenharia Florestal) - Universidade Federal do Paraná, Curitiba, 1980.

METCALFE, C.R.; CHALK, L. Anatomy of the Dicotyledons. Oxford: Clarendon Press, 1972. $1500 \mathrm{p}$.

METCALFE, C.R.; CHALK, L. Anatomy of the Dicotyledons. Oxford: Clarendon Press. 1957, p. 349-358.

MOLL, J.W.; JANSSONIUS, H.H. Mikrographie des Holzes der auf Java vorkommendes Baumarten, vol. 4. Leiden: E. J. Brill, 1926. 565 p.

NARDI, R.B.; EDLMANN, A.M. Legnami tropicali importati in Italia: anatomia e identificazione. vol. II. América Latina. Istituto di Assestamento e Tecnología Forestale. Firenze, Italia. 1992.

RECORD, S.J.; HESS, R.W. Timbers of the New World. New Haven: Yale University Press, 1943. $640 \mathrm{p}$.

RECORD, S.J., HESS, R.W. Timbers of The New World. New Haven: Yale University Press, 1949. $640 \mathrm{p}$.

RICHTER, H.G.; DALLWITZ, M.J. 2000 onwards. Commercial timbers: descriptions, illustrations, identification, and information retrieval. In English, French, German, Portuguese and Spanish. Version: 25th June 2009 "http://deltaintkey.com'.

SIEGLOCH, A.M.; MARCHIORI, J.N.C.; SANTOS, S.R. Anatomia do lenho de Cephalanthus glabratus (Spreng.) K. Schum. (Rubiaceae). Balduinia. n. 31, p.20-26, 2011.

SOLEREDER, H. Ein Beitrag zur anatomischen charakteristik und zur systematik der Rubiaceen. Bull. Herb. Boiss, v. 1, p. 167-183, 1893.

SOUZA, V.C.; LORENZI, H. Botânica Sistemática: Guia ilustrado para identificação das famílias de Fanerógamas nativas e exóticas no Brasil, baseado em APG II. Nova Odessa, São Paulo: Instituto Plantarum. 2008. 768 p.

TAYLOR, C.M.; CAMPOS, M.T.V.A.; ZAPPI, D. Flora da Reserva Ducke, Amazonas, Brasil: Rubiaceae. Rodriguésia, v. 58, n. 3, p.549-616, 2007.

TORTORELLI, L.A. Maderas y bosques argentinos. Buenos Aires: ACME, 1956. 910 p.

ZANG, S.; BAAS, P.; ZANDEE, M. Wood structure of the Rosaceae in relation to ecology, habit and phenology. IAWA Bulletin., v. 13, p. 307-349, 1992. 